Kazuhiro Murakami DDS, Tadanori Mammoto MD PhD, Takashi Kita MD,

Yuichirou Imai DDS, *

Takashi Mashimo MD PhD, $†$

Tadaaki Kirita DDS PhD, *

Masahito Sugimura DDS PhD, *

Yoshihiko Kishi MD

\section{Oral clonidine reduces the requirement of prostaglandin El for induced hypotension}

Purpose: To determine the effects of preanesthetic oral clonidine on the dose of prostaglandin EI (PGEI) required to produce hypotension during anesthesia.

Method: Oral placebo, $75 \mu \mathrm{g}$ or $150 \mu \mathrm{g}$ clonidine were administered 60 min prior to induction of anesthesia. Anesthesia was maintained with $\mathrm{O}_{2}: \mathrm{N}_{2} \mathrm{O}(30: 70)$ and isoflurane $1.0 \%$. After hemodynamic stabilization, an infusion of prostaglandin $\mathrm{El}$ was started $\left(0.05 \mu \mathrm{g} \cdot \mathrm{kg}^{-1} \cdot \mathrm{min}^{-1}\right)$ and the rate of infusion was adjusted to maintain mean arterial pressure (MAP) between $60-70 \mathrm{mmHg}$ during operation.

Results: Duration of hypotension in placebo, $75 \mu \mathrm{g}$ and $150 \mu \mathrm{g}$ preanesthetic oral clonidine treated groups were $132 \pm 46,117 \pm 37$ and $129 \pm 56 \mathrm{~min}$, respectively. The PGEI requirement in each group were $1563 \pm 180$ (28.6 \pm 3.2$), 594 \pm 197(10.8 \pm 3.6)$ and $283 \pm 30(5.5 \pm 3.6) \mu \mathrm{g}\left(\mathrm{ug}_{\mathrm{g}} \mathrm{kg}^{-1}\right)$, respectively. In addition, blood loss in each group were $|46| \pm 389,805 \pm 240$ and $931 \pm 40 \mathrm{ml}$, respectively.

Conclusion: Preanesthetic oral clonidine decreased the dose of PGEI required to produce hypotension, and decreased the blood loss during operation.

Objectif: Déterminer les effets de l'administration préanesthésique de clonidine orale sur la dose de prostaglandine EI (PGEI) nécessaire à la production d'hypotension pendant l'anesthésie.

Méthode : Un placebo oral, $75 \mu \mathrm{g}$ ou $150 \mu \mathrm{g}$ de clonidine ont été administrés $60 \mathrm{~min}$ avant linduction de l'anesthésie. L'anesthésie a été maintenue avec un mélange $\mathrm{O}_{2}: \mathrm{N}_{2} \mathrm{O}(30: 70)$ et de l'isoflurane à $1,0 \%$. Après la stabilisation des paramètres hémodynamiques, on a commencé la perfusion de prostaglandine $E \mid \quad(0,05$ $\mu \mathrm{g} \cdot \mathrm{kg}^{-1} \cdot \mathrm{min}^{-1}$ ) et le débit de la perfusion a été ajusté pour conserver la tension artérielle moyenne (TAM) entre 60-70 $\mathrm{mmHg}$ pendant l'intervention.

Résultats : La durée de l'hypotension avec le placebo ou $75 \mu \mathrm{g}$ ou 150 $\mu \mathrm{g}$ de clonidine préanesthésique orale a été de $132 \pm 46,117 \pm 37$ et de $129 \pm 56 \mathrm{~min}$, respectivement. Les besoins de PGEI dans chaque groupe ont été de $1563 \pm 180(28,6 \pm 3,2), 594 \pm 197(10,8 \pm 3,6)$ et de $283 \pm 30(5,5 \pm 3,6) \mu \mathrm{g}\left(\mathrm{ug}^{\mathrm{k}} \mathrm{kg}^{-1}\right)$, respectivement. De plus, la perte sanguine dans chaque groupe a été de $|46| \pm 389,805 \pm 240$ et de $93 \mid \pm 40 \mathrm{ml}$, respectivement.

Conclusion : L'administration préanesthésique de clonidine diminue la dose de PGEI nécessaire à la production d'hypotension et réduit la perte sanguine pendant l'opération.

From the Department of Anesthesiology, Osaka Medical Center for Cancer and Cardiovascular Diseases, Osaka, Department of Oral and Maxillofacial Surgery, ${ }^{*}$ Nara Medical University, Nara, and the Department of Anesthesiology, $†$ Osaka University, Osaka, Japan. Address correspondence to: Dr. Kazuhiro Murakami, Department of Anesthesiology, Osaka Medical Center for Cancer and Cardiovascular Diseases, 1-3-3, Nakamichi, Higashinari, Osaka 537-0025, Japan.

Phone: 81-6-6972-1181; Fax: 81-6-6972-7749; E-mail: mammoto@sahs.med.osaka-u.ac.jp

Accepted for publication July 30, 1999. 
I $\mathrm{N}$ clinical anesthesia, deliberate hypotension is applied in certain surgical procedures ${ }^{1}$ with the goal of reducing blood loss, thereby improving the condition of operative field or decreasing the need for blood transfusion. The potential for disease transmission by transfusion has made deliberate hypotension a more important technique than previously. Hypotension may be produced by a variety of techniques including epidural anesthesia ${ }^{2}$ and the use of high concentrations of anesthetic vapors. ${ }^{3}$ Recently, hemodynamic control has been improved by the use of short acting intravenous vasodilators such as PGEl.

The $\alpha_{2}$ adrenoceptor agonist, clonidine inhibits sympathetic neural activity and stabilizes the hemodynamic parameters during anesthesia. ${ }^{4}$ In animal studies, intravenous co-administration of clonidine reduces the dose of vasodilator required to induce hypotension. ${ }^{5}$ These findings imply that preanesthetic administration of clonidine is a useful adjuvant for deliberate hypotension. This study was designed to investigate the effect of orally administered clonidine on the dose of PGEl required to produce hypotension during radical hysterectomy.

\section{Patients and Methods}

The study was approved by the Institutional Review Board of the Osaka Medical Center for Cancer and Cardiovascular Diseases, and an informed consent was obtained.

Subjects consisted of $\mathbf{3 0}$ uterine cancer patients scheduled for radical hysterectomy and pelvic lymphadenectomy (ASA Physical status I or II, 34-65 yr old women). Patients were excluded if they manifested one of the following: hypertension, diabetes mellitus, organic heart disease, ECG or renal abnormalities or any gastrointestinal abnormality that would hinder enteric absorption of oral medication. The patients were randomly assigned to one of the following groups.

1 - Control: placebo po $60 \mathrm{~min}$ before induction of anesthesia $(\mathrm{n}=10)$.

2 - Clonidine 75: $75 \mu \mathrm{g}$ clonidine po as in placebo group $(\mathrm{n}=10)$.

3 - Clonidine 150: $150 \mu \mathrm{g}$ clonidine $p o$ as in placebo group $(n=10)$ :

Anesthetic management of these groups was otherwise identical. In the operating room, all patients were monitored with lead II ECG, and noninvasive blood pressure. After insertion of an intravenous catheter, an epidural catheter was positioned at $\mathrm{T}_{11-12}$ or $\mathrm{T}_{12}-\mathrm{L}_{1}$ interspace.

Anesthesia was induced with $2 \mu \mathrm{g} \cdot \mathrm{kg}^{-1}$ fentanyl and $4 \mu \mathrm{g} \cdot \mathrm{kg}^{-1}$ pentobarbital. After patients lost consciousness, $0.1 \mathrm{mg} \cdot \mathrm{kg}^{-1}$ vecuronium was administered to facilitate tracheal intubation. Respiratory gas monitor (A Hewlet Packered M1026, MA, USA) was used to monitor inspired oxygen concentration, continuous capnography, inspired and end-tidal nitrous oxide concentration, and tidal volume. Oxygen saturation was monitored by pulse oxymetry (A Hewlett Packered M1026, MA, USA). Lungs were mechanically ventilated to maintain end-tidal $\mathrm{CO}_{2}$ between $35-40 \mathrm{mmHg}$. Arterial and central venous catheters were inserted for monitoring blood pressure and administration of vasodilators, respectively.

Anesthesia was maintained with $\mathrm{O}_{2}: \mathrm{N}_{2} \mathrm{O}(30: 70)$ and isoflurane ( $1 \% \mathrm{ET})$. Additional vecuronium was used for muscle relaxation and fentanyl was administered as needed.

After stabilizing the hemodynamics, the infusion of prostaglandin El was started at $0.05 \mu \mathrm{g} \cdot \mathrm{kg}^{-1} \cdot \mathrm{min}^{-1}$, and the rate of infusion was adjusted to maintain the mean arterial pressure (MAP) between $60-70 \mathrm{mmHg}$ by one of two staff anesthesiologist, who were blinded as to the kind of premedicant used. In case of severe hypotension ( $<40 \mathrm{mmHg} \mathrm{MAP}$ ) or severe bradycardia (< $40 \mathrm{bpm})$, the infusion was stopped and $4 \mathrm{mg}$ ephedrine was administered. The infusion of PGEl was stopped at the completion of hemostasis and $5 \mathrm{ml}$ lidocaine $1 \%$ and $2 \mathrm{mg}$ morphine were administered through epidural catheter for postoperative analgesia. Initial blood loss was replaced with crystalloid until the estimated blood loss was great enough to result in a hematocrit of $25 \%$ or less. Blood transfusion was begun if the hematocrit was $<25 \%$. After the operation, neuromuscular blockade was antagonized by $2.5 \mathrm{mg}$ neostigmine and $\mathrm{lmg}$ atropine and were extubated. During the perioperatrive period, hemodynamic data (blood pressure and heart rate) were recorded (Hewlett Packered, M1026, MA, USA.).

Demographic data of the patients (age, height, weight, duration of anesthesia, operation and induced hypotension, infusion volume, urine output and doses of fentanyl) were examined by analysis of variance (ANOVA), and the distribution of patients regard to ASA physical status, episodes of hypotension were compared among the group using Chi-square analysis. For hemodynamic parameters (MAP and HR), the unpaired $t$ test was used to compare the groups. Dose of PGEl in each group was examined by ANOVA, and comparisons between groups were assessed by the Bonferroni-Dunn test.

\section{Results}

No differences existed in the demographic data among groups except in blood loss (Table I). There were no differences in the duration of anesthesia, operation and 
TABLE I Patient profiles

\begin{tabular}{|c|c|c|c|}
\hline & \multirow[t]{2}{*}{ control } & \multicolumn{2}{|l|}{ clonidine } \\
\hline & & $75 \mu g$ & $150 \mu g$ \\
\hline Number & 10 & 10 & 10 \\
\hline $\operatorname{Age}(y r)$ & $52 \pm 7$ & $54 \pm 6$ & $54 \pm 12$ \\
\hline Height $(\mathrm{cm})$ & $157 \pm 5$ & $155 \pm 5$ & $154 \pm 6$ \\
\hline Weight (kg) & $55 \pm 8$ & $55 \pm 6$ & $52 \pm 8$ \\
\hline \multicolumn{4}{|l|}{ ASA physical status } \\
\hline I & 5 & 7 & 5 \\
\hline II & 5 & 3 & 5 \\
\hline Dose of fentanyl $\left(\mu \mathrm{g} \cdot \mathrm{kg}^{-1}\right)$ & 3.7 & 3.6 & 3.7 \\
\hline \multicolumn{4}{|l|}{ Duration of } \\
\hline operation (min) & $203 \pm 64$ & $179 \pm 40$ & $187 \pm 76$ \\
\hline anesthesia (min) & $256 \pm 65$ & $231 \pm 36$ & $249 \pm 81$ \\
\hline hypotension & $132 \pm 46$ & $117 \pm 37$ & $129 \pm 56$ \\
\hline Blood loss (ml) & $1461 \pm 389$ & $805 \pm 240$ & $931 \pm 40^{*}$ \\
\hline Infused volume $(\mathrm{ml})$ & $2914 \pm 733$ & $2015 \pm 281$ & $2767 \pm 1040$ \\
\hline Urine volume (ml) & $612 \pm 233$ & $400 \pm 179$ & $413 \pm 382$ \\
\hline
\end{tabular}

Values are expressed as mean $\pm \mathrm{SD},{ }^{\star} P<0.05$ compared with control group.

TABLE II Hemodynamic variables

\begin{tabular}{llll}
\hline & control & \multicolumn{2}{c}{ clonidine } \\
& & $75 \mu g$ & $150 \mu g$ \\
\hline Before premedication & & & \\
$\quad$ MAP & $92 \pm 11$ & $88 \pm 11$ & $91 \pm 11$ \\
HR & $68 \pm 8$ & $69 \pm 7$ & $70 \pm 8$ \\
Before induction & & & \\
$\quad$ MAP & $97 \pm 10$ & $92 \pm 9$ & $85 \pm 10^{*}$ \\
HR & $83 \pm 6$ & $70 \pm 7^{\star}$ & $74 \pm 9^{\star}$ \\
Post induction & & & \\
$\quad$ MAP & $77 \pm 7$ & $72 \pm 8$ & $71 \pm 12$ \\
HR & $75 \pm 8$ & $68 \pm 9$ & $69 \pm 11$ \\
Post intubation & & & \\
$\quad$ MAP & $100 \pm 10$ & $85 \pm 7^{\star}$ & $80 \pm 8^{*}$ \\
HR & $82 \pm 7$ & $78 \pm 9$ & $81 \pm 12$ \\
Post incision & & & \\
$\quad$ MAP & $68 \pm 6$ & $67 \pm 9$ & $66 \pm 5$ \\
HR & $65 \pm 8$ & $59 \pm 9$ & $60 \pm 8$ \\
Episodes of hypotension & 4 & 3 & 4 \\
\hline
\end{tabular}

MAP: mean arterial pressure, HR heart rate

Values are expressed as mean $\pm S D$. ${ }^{*} P<0.05$ compared with control

deliberate hypotension, or in the dose of fentanyl (Table I). The mean blood losses for the control, 75 and $150 \mu \mathrm{g}$ clonidine groups were $1460 \pm 389,805 \pm$ 239 and $931 \pm 40(\mu \mathrm{g})$, respectively $(P<0.01)$.

In each group, the infusion of PGEl was started after the skin incision and the durations of hypotension in control, $75 \mu \mathrm{g}$ and $150 \mu \mathrm{g}$ clonidine groups were $132 \pm 46,117 \pm 37$ and $129 \pm 56 \mathrm{~min}$, respectively (Table I). The total requirements for PGEI for deliberate hypotension in each group were $1563 \pm$

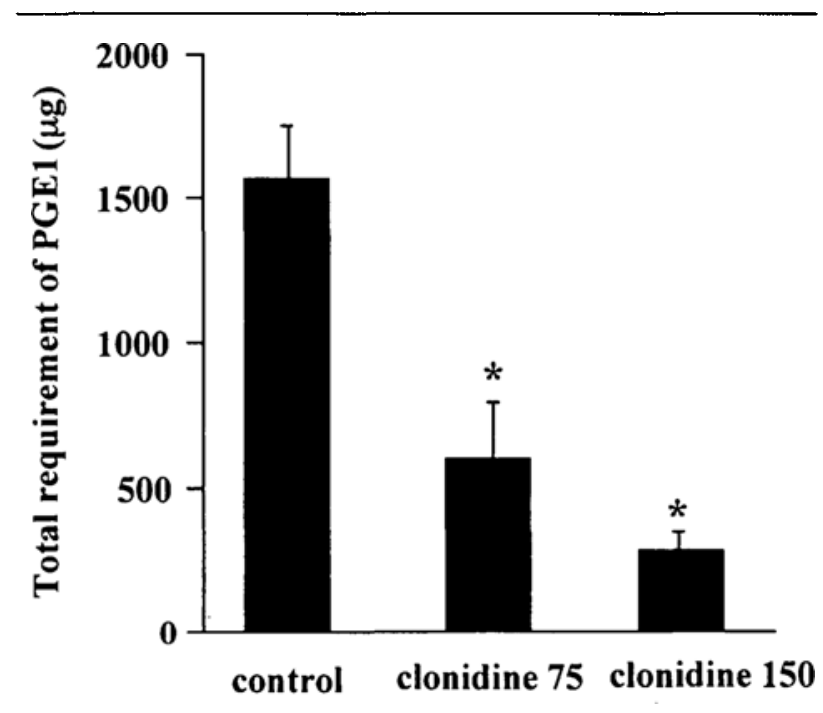

FIGURE 1 The total requirement of PGEI $(\mu \mathrm{g})$ for deliberate hypotension in the control and clonidine treated groups (75 and $150 \mu \mathrm{g})$. The values are expressed as mean $\pm \mathrm{SEM},{ }^{\star} P<0.01$ compared with control ( $\mathrm{n}=10$ in each group).

$180(28 \pm 3), 594 \pm 197(10 \pm 3)$, and $283 \pm 3(5.5$ $\pm 3) \mu \mathrm{g}\left(\mu \mathrm{g} \cdot \mathrm{kg}^{-1}\right)$, respectively (Figure $1, P<0.01$ ). The mean infusion rates in these groups were 0.336 , 0.086 and $0.038 \mu \mathrm{g} \cdot \mathrm{kg}^{-1} \cdot \mathrm{min}^{-1}$, respectively.

There were no differences in mean arterial pressure (MAP) and heart rate (HR) among groups before premedication (Table II). At the preinduction period, $150 \mu \mathrm{g}$ clonidine reduced MAP and $\mathrm{HR}$, and $75 \mu \mathrm{g}$ clonidine reduced HR (Table II, $P<0.05$ ). At the postinduction and post incision period, no differences among groups existed in MAP and HR (Table II). In addition, 75 and $150 \mu \mathrm{g}$ clonidine attenuated the increase in MAP during tracheal intubation (Table II, $P<0.05$ ). During deliberate hypotension, MAP was identical in each group while HR tended to be lower in the clonidine treated groups (Figure 2, $P<0.05$ at $60 \mathrm{~min}$ in $150 \mu \mathrm{g}$ clonidine group, no differences at other points). No differences existed among groups in the number of episodes of hypotension (Table II).

\section{Discussion}

Our results indicated that preanesthetic oral clonidine (75 and $150 \mu \mathrm{g}$ ) decreased the requirement for PGE1 to produce deliberate hypotensionn. In addition, clonidine attenuated the hemodynamic responses to tracheal intubation and reduced blood loss during operation.

The $\alpha_{2}$ adrenoceptor agonist, clonidine is known to inhibit sympathetic neural activity and, consequently, stabilizes hemodynamic variables during anesthesia. ${ }^{4}$ 

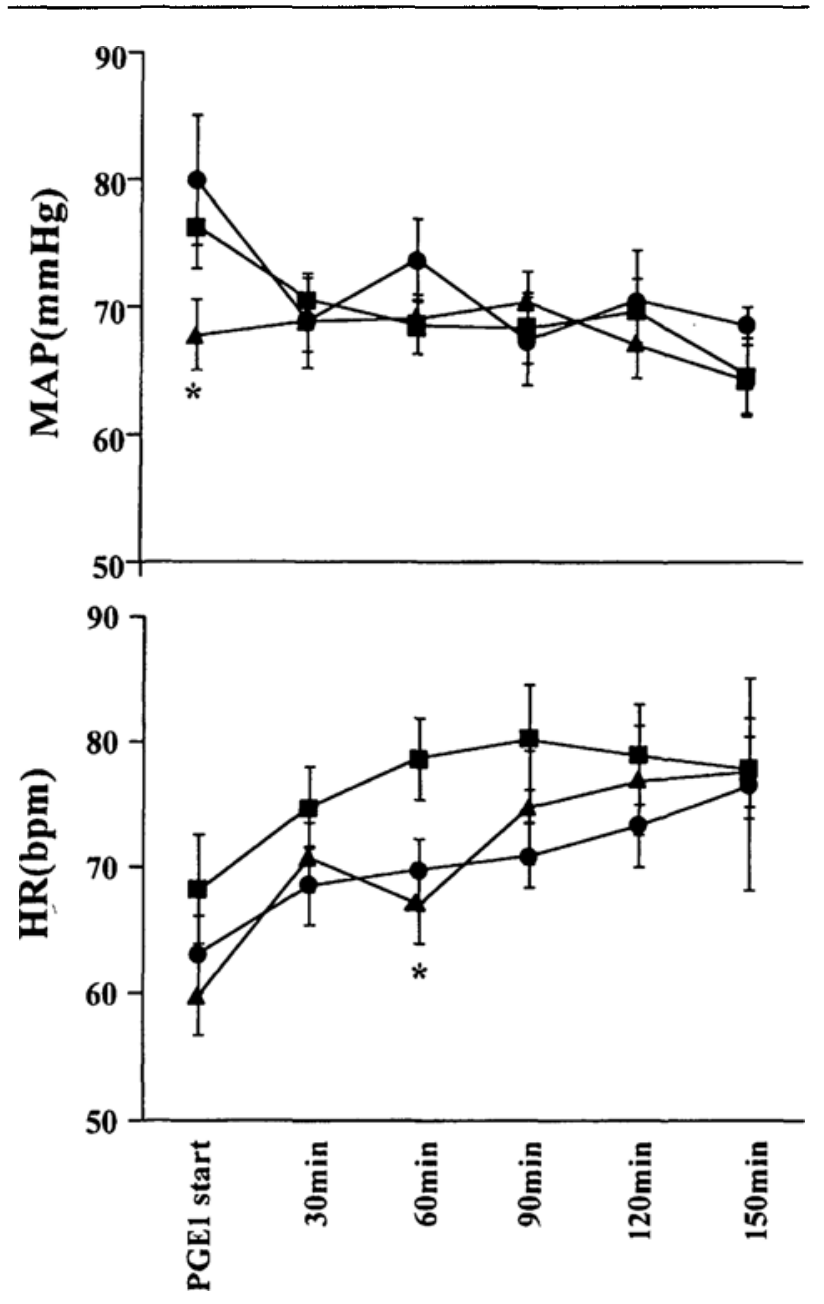

FIGURE 2 The mean arterial pressure and heart rate (HR) during deliberate hypotension in the control and clonidine treated groups ( 75 and $150 \mu \mathrm{g}$ ) ( $\boldsymbol{0} \cdot$ : control, 0 : clonidine $75 \mu \mathrm{g}$, $\Delta \cdot$ : clonidine $150 \mu \mathrm{g}$ ). The values are expressed as mean \pm SEM, ${ }^{*} P<0.05$ compared with control ( $\mathrm{n}=10$ in each group)

Clonidine also decreased the release norepinephrine and enhanced baroreflex in animal investigation. ${ }^{6,7}$ These properties would be responsible for the vasodilator sparing actions of clonidine in this study.

In addition to sympatholytic actions, clonidine exerts hypnosis and analgesia via activation of $\alpha_{2}$ adrenoceptors in the central nervous system. ${ }^{8,9}$ In the clinical setting, preanesthetic clonidine reduces the requirement of volatile anesthetics and/or opioid. ${ }^{4}$ Recently, we reported that preanesthetic oral cloni- dine $(150 \mu \mathrm{g})$ relieved anxiety and reduced the dose of propofol required for minor surgery. ${ }^{10}$ These properties might affect the depth of anesthesia and, consequently, reduce the dose of PGEI required to produce hypotension. In this study, the hemodynamic responses to skin incision were identical in each group and the maintenance of anesthesia (isoflurane 1\% ET and nitrous oxide $70 \%$ with $4 \mu \mathrm{g} \cdot \mathrm{kg}^{-1}$ fentanyl) was sufficient for surgery. Thus, it is speculated that, at the doses we used, clonidine exerted its beneficial action primarily by inhibiting the sympathetic neural activity.

Although the main goal of deliberate hypotension is to reduce blood loss, blood flow to organs such as brain, liver and kidney should be preserved and hypotension should be easily controlled. Therefore, short acting vasodilators are ideal for producing deliberate hypotension. Among several short acting vasodilators, PGEl preserves organ blood flow, and protects these organs. ${ }^{11,12,13}$ It has been reported that PGEl preserves the local cerebral blood flow without changing $\mathrm{CO}_{2}$ reactivity of the cerebral vessels during deliberate hypotension ${ }^{14}$ and maintains the spinal and epidural blood flow. ${ }^{15,16}$ In addition, PGEl protects against ischemic liver injury ${ }^{11}$ and preserves renal function. ${ }^{12}$ Therefore, PGEl is often infused during liver and renal transplantation. ${ }^{17,18}$ Other vasodilators, such as sodium nitroprusside, do not protect the visceral organs during deliberate hypotension. ${ }^{19}$ In this study, the mean infusion rates of PGEl in the clonidine treated groups were $0.086(75 \mu \mathrm{g})$ and 0.038 $(150 \mu \mathrm{g}) \mu \mathrm{g} \cdot \mathrm{kg}^{-1} \cdot \mathrm{min}^{-1}$. Considering that optimal dose of PGEI to maintain visceral organ blood flow is approximately $0.01 \mu \mathrm{g} \cdot \mathrm{kg}^{-1} \cdot \mathrm{min}^{-1},{ }^{20}$ blood flow to the kidney and liver would be preserved in the clonidine treated groups during hypotension. Therefore, we consider that PGEl is an ideal vasodilator for deliberate hypotension. However, the vasodilating action of PGEl is mild and a larger dose $\left(>0.1 \mu \mathrm{g} \cdot \mathrm{kg}^{-1} \cdot \mathrm{min}^{-1}\right)$ would be needed to induce hypotension without clonidine. The cost of PGEl would limit the usage of this agent for deliberate hypotension. The cost of clonidine $(75 \mu \mathrm{g}=0.42 \$)$ is low compared with that of PGEl $(500 \mu \mathrm{g}=277 \$)$. Our results indicated that preanesthetic medication of clonidine reduced the cost of PGEl. The use of preanesthetic clonidine would resolve the problems of the cost of vasodilators in producing deliberate hypotension.

In conclusion, administration of clonidine (75 and $150 \mu \mathrm{g})$ po before anesthesia reduced the dose of PGEl required to maintain hypotension and decreased blood loss during surgery. These findings indicate that clonidine is a useful adjuvant in producing deliberate hypotension with PGEl. 


\section{Acknowledgements}

The authors are indebted to Drs. Saji and Kagawa for their helpful comments on our manuscript. We also wish to thank Miss Uemura and Drs. Oohata, Yamamura and Nakagawa for their assistance throughout this investigation.

\section{References}

1 Powell JL, Mogelnicki SR, Franklin EW III, Chambers $D A$, Burrell MO. A deliberate hypotensive technique for decreasing blood loss during radical hysterectomy and pelvic lymphadenectomy. Am J Obstet Gynecol 1983; 147: 196-202.

2 Sharrock NE, Mineo $R$, Urqubart $B$, Salvati $E A$. The effect of two levels of hypotension on intraoperative blood loss during total hip arthroplasty performed under lumbar epidural anesthesia. Anesth Analg 1993; 76: $580-4$.

3 Lam AM, Gelb AW. Cardiovascular effects of isoflurane-induced hypotension for cerebral aneurysm surgery. Anesth Analg 1983; 62: 742-8.

4 Howie $M B$, Hiestand DC, Jopling $M W$, Romanelli VA, Kelly WB, MCSweeney TD. Effect of oral clonidine premedication on anesthetic requirement, hormonal response, hemodynamics, and recovery in coronary artery bypass graft surgery patients. J Clin Anesth 1996; 8: 263-72.

5 Bloor BC, Finander LS, Flacke WE, Van Etten A. Effect of clonidine on sympathoadrenal response during sodium nitroprusside hypotension. Anesth Analg 1986; 65 : 469-74.

6 Tsyrlin VA, Bravkov MF. Effects of alpha-adrenoceptorstimulating drugs on baroreceptor reflexes in conscious cats. Eur J Pharmacol 1980; 67: 75-83.

7 Sleight P, West MJ, Korner PI, Oliver JR, Chalmers JP, Robinson JL. The action of clonidine on the baroreflex control of heart rate in conscious animals and man, and on single aortic baroreceptor discharge in the rabbit. Arch Int Pharmacodyn Ther 1975; 214: 4-11.

8 Doze VA, Chen BX, Maze M. Dexmedetomidine produces a hypnotic-anesthetic action in rats via activation of central alpha-2 adrenocepters. Anesthesiology 1989; 71: 75-9.

9 Mastrianni JA, Abbott FV, Kunos G. Activation of central mu-opioid receptors is involved in clonidine analgesia in rats. Brain Res 1989; 479: 283-9.

10 Imai $Y$, Mammoto $T$, Murakami $K$, et al. The effects of preanesthetic oral clonidine on total requirement of propofol for general anesthesia. J Clin Anesth 1998; 10: 660-5.

11 Sugawara $\Upsilon$, Kubota $K$, Ogura $T$, et al. Protective effect of prostaglandin El against ischemia/reperfusion-induced liver injury: results of a prospective, ran- domized study in cirrhotic patients undergoing subsegmentectomy. J Hepatol 1998; 29: 969-76.

12 Hayashida $M$, Hanaoka $K$, Shimada $\Upsilon$, Namiki $A$, Amaha $K$. The effect of low-dose prostaglandin El on intra- and post-operative renal function. (Japanese) Masui 1997; 46: 464-70.

13 Hotta K, Mitsubata $H$, Saitob J, et al. Prostaglandine El-induced hypotension well maintains cerebral circulation and carbon dioxide reactivity in non-neurosurgical patients under sevoflurane-anesthesia. (Japanese) Masui 1997; 46: 193-8.

$14 A b e K$, Demizu A, Yoshiya I. Effect of prostaglandin $\mathrm{El}$-induced hypotension on carbon dioxide reactivity and local cerebral blood flow after subarachnoid haemorrhage. Br J Anaesth 1992; 68: 268-71.

15 Abe K, Kakiuchi $M$, Shimada $\Upsilon$. Epidural blood flow during prostaglandin El or trimethaphan induced hypotension. Prostaglandins Leukot Essent Fatty Acids 1994; 50: 199-202.

16 Abe K, Nishimura $M$, Kakiwchi $M$. Spinal cord blood flow during prostaglandin El induced hypotension. Prostaglandins Leukot Essent Fatty Acids 1994; 51: 173-6.

17 Merion RM. Prostaglandins in liver transplantation. Adv Exp Med Biol 1997; 433: 13-8.

18 Polyak MM, Arrington BO, Stubenbord WT, Kinkhabwala $M$. Prostaglandin El improves pulsatile preservation characteristics and early graft function in expanded criteria donor kidneys. ASAIO J 1998; 44: M610-12.

19 Kimura $H$, Kohyama A. Effects of deliberate hypotension on the ischemic heart during isoflurane anesthesia - a comparison of prostaglandine E1 and sodium nitroprusside. (Japanese) Masui 1992; 41: 1397-405.

20 Hayashida $M$, Hanaoka $K$, Shimada $\Upsilon$, Namiki $A$, Amaba $K$. The effect of low-dose Prostaglandin El on intra- and post-operative liver function. (Japanese) Masui 1997; 46: 618-27. 